Plant Tissue Cult. \& Biotech. 30(2): 167-177, 2020 (December)

(CBangladesh Assoc. for Plant Tissue Culture \& Biotechnology
$\overline{\mathrm{PTC \& B}}$

\title{
In vitro Propagation of Mortiño (Vaccinium floribundum Kunth.)
}

\section{Susana Llivisaca, Juan Cevallos-Cevallos ${ }^{1 *}$, Joffre Mendoza ${ }^{1}$, Fernando Piña, Esther Peralta, Eduardo Sanchez-Timm ${ }^{1}$ and José Flores ${ }^{1}$}

\author{
Escuela Superior Politécnica del Litoral, ESPOL, Centro de Investigaciones Biotecnológicas del \\ Ecuador (CIBE), Campus Gustavo Galindo, Km. 30.5 vía Perimetral, Apartado 09-01-5863. \\ Guayaquil, Ecuador
}

Key words: Carbendazim, Fungicide, Chlorine dioxide, Semi-solid medium

\begin{abstract}
The disinfected axillary shoots of mortino - a wild plant species were cultured in MS with different concentrations $(0.002,0.05$ and $0.1 \%)$ of methyl $\mathrm{N}-(1 \mathrm{H}-$-benzimidazol-2-yl) carbamate to develop an in vitro protocol for micropropagation through organogenesis. They were then placed in a concentration matrix $(0.1,1.0$ and $10.0 \mu \mathrm{M})$ whose factorial design involved BAP and IAA in WPM. Results showed a 100\% disinfection at $0.05 \%$ concentrations of carbendazim and the combination of IAA and BAP at $10 \mu \mathrm{M}$ yielded a multiplication factor of 3.35, with rooting after seven weeks. This system showed efficient disinfection, multiplication and yielding an acceptable root system.
\end{abstract}

\section{Introduction}

Mortino (Vaccinium floribundum Kunth.) - a wild plant species belongs Ericaceae (Castro and Álvarez 2013), which includes different species of the Andean region such as V. ashei, $V$. angustifolium, and $V$. corymbosum (Medina et al. 2015). Mortiño is an endemic species that grows spontaneously in the South American Tundra. This species is considered in a state of strong process of genetic erosion (Cobo et al. 2016).

Mortiño plants produce a nutritive and sweet berry, which is $5 \mathrm{~mm}$ in diameter and dark purple, commonly used in the preparation of jams, alcoholic beverages, and other food products. Mortiño fruits are considered to be an important source of bioactive compounds (Howell 2009), such as polyphenols and antioxidants. Furthermore, they

*Author for correspondence: <jmceva@espol.edu.ec>. ${ }^{1}$ Escuela Superior Politécnica del Litoral, ESPOL, Facultad Ciencias de la Vida (FCV), Campus Gustavo Galindo, Km. 30.5 vía Perimetral, Apartado 09-01-5863. Guayaquil, Ecuador.

DOI: https://doi.org/10.3329/ptcb.v30i2.50687 
have been associated to the reduction of muscular dystrophy, cancer, Alzheimer's, neurological damage, diabetes, and cataracts in humans (Silva et al. 2015). Other studies have shown that $V$. floribundum phytochemicals can limit adipogenesis and inflammatory pathways in vitro (Schreckinger et al. 2010).

Mortiño plants are also a source of antimicrobial compounds. Fruits and leaves extracts from mortiño have significantly inhibited the growth of Gram-negative bacteria including Burkholderia gladioli, Burkholderia cepacia, Salmonella Typhimurium, Vibrio parahaemolyticus, Vibrio harveyi, Vibrio vulnificus, Escherichia coli, and Pseudomona aeruginosa, as well as Gram-positive bacteria such as Probionibacterium propionicum, Staphylococcus aureus, and Enterococcus faecalis, showing greater inhibition halos than those produced by the antibiotic ampicillin (Llivisaca et al. 2018).

Micropropagation of blueberry plants was first reported about 30 years ago, showing that organogenic-based micropropagation methods do not cause genetic variability (Rodríguez and Morales 2015). Micropropagation studies on $V$. floribundum have been inconclusive, suggesting that additional research is needed (Torres et al. 2010).

The objective of this study was to establish a protocol for in vitro propagation of Vaccinium floribundum using an organogenesis strategy. The beneficiaries of this study would be small and medium farmers, because they would obtain homogeneous, highly productive, and pathogens free plants for commercial production (Ruiz 2011). On the other hand, consumers would get the benefit of enjoying the nutraceutical advantages of an important functional food (Silva et al. 2015). Moreover, mortiño cultivation in plots will reduce the erosion that the tundra is currently suffering, and it may improve the percentage of captured water in cultivated areas at the mountain region, especially in important cities such as Quito and Cuenca (Podwojewski 1999).

\section{Materials and Methods}

Plants were obtained from a nursery located at Machachi city, situated at the Ecuadorian highlands. The nursery got the plants from indigenous people, who live in the tundra, and they multiplied their plants from wild shrubs. Therefore, the substrate comprised the same soil of the tundra and were transferred to greenhouses at Guayaquil city, placed in the coastal region. Plants were 30 to $40 \mathrm{~cm}$ height and were kept in the greenhouse at $25^{\circ} \mathrm{C}$ with $12 \mathrm{hrs}$ of photoperiod.

Plants were watered three times a week and fertilized with $10 \%$ organic compost tea, twice a month, for a 45-day adaptation period. The presence of cuttings was constant after the quarantine (from day 45).

Cuts of axillary shoots were obtained from the acclimated plants in the greenhouse, and they were sectioned to an approximate size of 3 to $5 \mathrm{~cm}$ in length and washed in a continuous flow of tap water and neutral detergent. The explants were then subjected to two types of disinfection strategies, based on a random design for the $\mathrm{ClO}_{2}$ treatment (Merck, Darmstadt, Germany), and for the treatment with the fungicide carbendazim 
(Carbenex, Hangzhou, China). The first design comprised three cuttings immersed in water with $2 \% \mathrm{ClO}_{2}$ for 10,20 and $30 \mathrm{~min}$. Then, the explants were placed in $2 \%$ hypochlorite for seven minutes followed by $70 \%$ ethanol for one minute, and rinsed four times with sterile distilled water according to Castro and Álvarez (2013). The mortality and disinfection percentages were calculated by the number of live cuttings in each of the treatments of the disinfection stage.

For the execution of the second experimental design, the cuts disinfected with the treatment of 10 minutes with chlorine dioxide were placed in sterile jars, that contained MS with $0.02,0.5$ and 1.0\% carbendazim (Debergh et al. 1993), with 2 or 1\% phytagel (solid and semi-solid, respectively) at $20^{\circ} \mathrm{C}$ and a photoperiod of $12 \mathrm{hrs}$ /ight for 2 weeks (Angulo et al. 2015). The disinfection was measured as the presence or absence of contamination in the media. Three replications were made for each concentration of carbendazim, where five cuttings were placed in each flask, with a total of 15 plants per treatment.

For the multiplication and rooting of the cuttings, the plant material was placed in modified WPM semi-solid culture media and supplemented with pairwise combinations of BAP $(0.1,1.0$ and $10 \mu \mathrm{M})$ with IAA $(0.1,1.0$ and $10 \mu \mathrm{M})$. For this assay, five cuttings were placed in each flask, with five replicas for each combination, with a total of 45 flasks. The $\mathrm{pH}$ of the media was adjusted to 5.9 prior to autoclaving (Brand: Market Forge; Model: STM-EL) at $121^{\circ} \mathrm{C}$ and $1.05 \mathrm{~kg} / \mathrm{cm}^{2}$ of pressure for $20 \mathrm{~min}$ (Korneva et al. 2013).

For the induction of roots of the explants obtained at the multiplication stage, a common strategy was used in the in vitro propagation, based on allowing the explants to continue for an extended period of time ( 2.5 months) in the same medium used in the multiplication stage, the decay of the nutrients present in the media is known to induce rooting. In addition, the WPM is ideal for this stage because its low amount of nutrients increases the percentage of rooting (Acosta et al. 2011). The presence and absence of roots was recorded for each treatment.

The statistical design of the chlorine dioxide and carbendazim in vitro tests were completely randomized. For the $\mathrm{ClO}_{2}$ test, the studied factor was the time and it was divided in three levels (10, 20 and $30 \mathrm{~min}$ ), and the response variables were the percentage of $\mathrm{ClO}_{2}(2 \%)$ disinfection and the percentage of mortality. For the carbendazim test, the study factor was the fungicide concentration in three levels $(0.002$, 0.05 and $0.1 \%$ ) tested in two types of culture media (solid and semi-solid) and the response variable was the percentage of disinfection.

On the other hand, a factorial design was applied to the matrix of plant growth regulators concentrations (BAP and IAA) where the multiplication rate data was obtained by counting the number of new buds generated from the originals. The multiplication rate was calculated by dividing the number of buds obtained by the 
number of original buds. The analysis of the significant difference proposed by Tukey using the software Minitab 16.

\section{Results and Discussion}

Microbial contamination is one of the most serious problems of plant tissue culture, even more when the plant material comes from the field and is used as a direct source of explants to produce in vitro seedlings.

Different disinfection protocols are available with numerous weaknesses and failures on the levels of disinfection for the same plant species (Silva et al. 2015). Therefore, disinfection is one of the most critical stages, especially when dealing with wild and recalcitrant species (Litwińczuk 2012).

The disinfection with $\mathrm{ClO}_{2}(2 \%)$ did not show a significant difference between the tested trials of 20 and $30 \mathrm{~min}$ of immersion, but there was a significant difference between the $10 \mathrm{~min}$ test and the 20 and $30 \mathrm{~min}$ immersion tests.

In terms of mortality, the three treatments differ significantly $(\mathrm{p}>0.05)$. It is important to emphasize that although there was disinfection in the 20 and $30 \mathrm{~min}$ immersions (Fig. 1), it also killed the explants, which is incongruent with the $24 \mathrm{hrs}$ of immersion that they subjected to the explants in the methodology applied by Castro and Álvarez (2013).

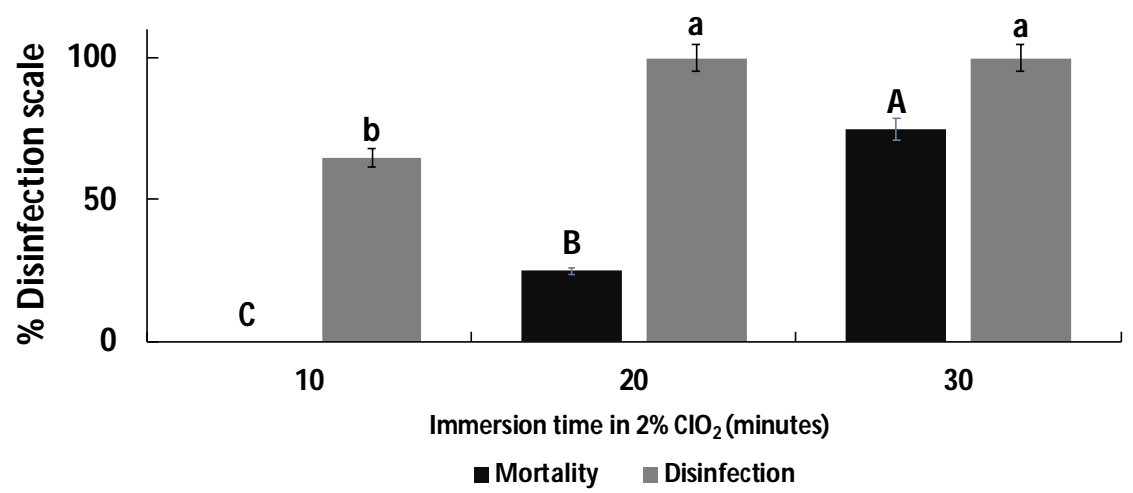

Fig. 1. Effect of $2 \%$ chlorine dioxide on disinfection of explants of $V$. floribundum. Different letters at the top of each column represent significant differences $(p<0.05)$ in the percentages of mortality $(A, B$ and $C)$ and in the percentages of disinfection $(a, b$ and $c)$.

It is relevant to indicate that $100 \%$ disinfection was reached when the explants, disinfected with $2 \% \mathrm{ClO}_{2}$ for 10 minutes, were subsequently placed in the MS with carbendazim (Fig. 2).

It should be noted that the cuttings for this assay came from wild plants, which usually carry pathogens that must be removed by a series of systematic methods. (Angulo et al. 2015). Liquid chlorine dioxide $\left(\mathrm{ClO}_{2}\right)$ is a fungicide, bactericidal and 
viricidal compound that is very stable in solutions with a $\mathrm{pH}$ between 3.0 and 9.0. This chemical is more effective than an antiseptic with a neutral $\mathrm{pH}$ (Cardoso and Teixeira 2012), and is efficient in the presence of organic matter without the risk of chloramine production (Tecsaclor 2009).

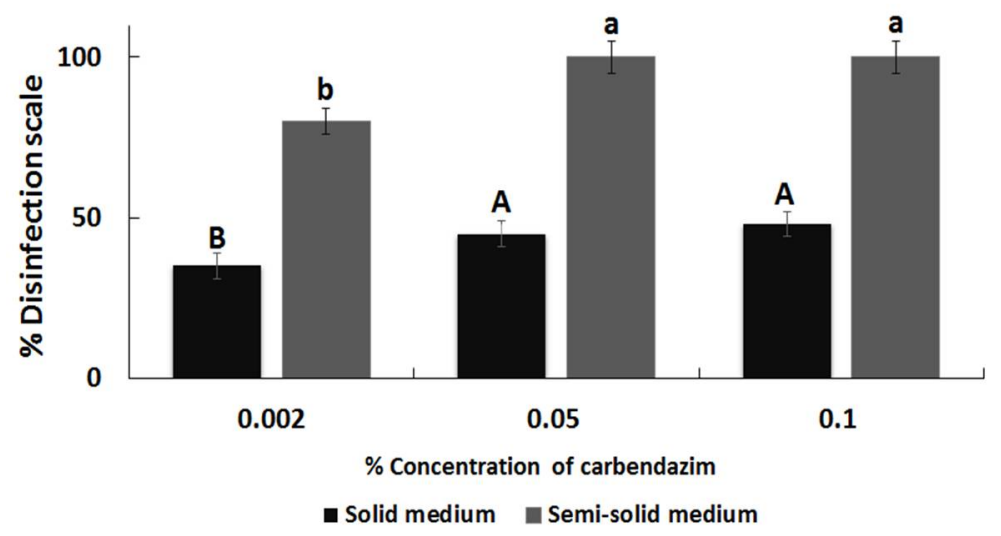

Fig. 2. Effect of carbendazim on the disinfection of explants of $V$. floribundum. Different letters at the top of each column represent significant differences $(p<.05)$ in the percentages of disinfection in the solid medium ( $\mathrm{A}, \mathrm{B}$ and $\mathrm{C})$ and in the percentages of disinfection in the semi-solid medium $(\mathrm{a}, \mathrm{b}$ and $\mathrm{c})$.

Hypochlorite is known to be the most commonly used surface disinfectant for in vitro culture, applied alone or in combination with ethanol (70\%). However, mortiño needs a disinfection strategy that is different from the usual cultures (only ethanol and sodium hypochlorite), and it should not affect the establishment of explants. Results are similar to the reported in previous studies that used $2 \% \mathrm{ClO}_{2}$ as a disinfectant without damage or obvious changes in the propagules (Cardoso and Teixeira 2012).

Research on Anthurium species indicated that there is less disruptions on propagules when chemical sterilization is used, because they cause less changes on the chemical composition of cuttings once they are in contact while absorbing the $\mathrm{ClO}_{2}$ or the composition chemical of the culture media (Silva et al. 2015). In addition, (Srichuay et al. 2018), showed that the culture medium sterilized with $\mathrm{ClO}_{2}$ promoted the formation of shoots, even that the culture medium supplemented with $10 \mathrm{ppm}$ of $\mathrm{ClO}_{2}$ could induce rooting in $100 \%$.

Carbendazim is the fungitoxic ingredient originated from different active principles (Castro and Álvarez 2013). In this study carbendazim yielded 35, 45 and 48\% disinfection at $0.002,0.05$ and $0.1 \%$ fungicide concentration, respectively in solid media. Similarly, when used in semi-solid media, disinfection percentages of 80,100 and $100 \%$ for 0.002 , 0.05 and $0.1 \%$ carbendazim, respectively. Significant differences in disinfection were only observed when comparing 0.002 and $0.05 \%$ carbendazim treatments in both solid and semi-solid media. 
Carbendazim has been used in other ways such as to spray mother trees or soak axillary buds before placing them into culture media, obtaining $45.63 \%$ fungal contamination by spraying papaya mother trees four times and soaking the axillary buds for $30 \mathrm{~min}$ in a $0.1 \%$ carbendazim solution (Babu et al. 2004). A similar experiment performed by Saha and Behera 2015, who combined gentamicin spray (100 mg/) + stirring of explants in carbendazim $(0.2 \%)+$ mancozeb $(0.2 \%)$, argued that it was the best pre-treatment for cultures, even if the obtained results were $57.96 \%$ disinfection.

This improvement of the disinfection rate of the explants, is due to the fact that the semi-solid medium facilitated the absorption of the fungicides by the cuttings tissue, which was faster than the growth rate of the invasive fungus (Cardoso and Teixeira 2012).

Finally, Debergh et al. (1993) verified that this product can be autoclaved without any loss of activity and there is no degradation of the product during a normal culture period of 32 days. In addition, the studied species (C. terminalis and P. avium) did not reveal any phytotoxic effect, and that the number of shoots (less than $15 \mathrm{~mm}$ ) increased significantly.

The most successful disinfection strategy applied in this study was composed of semi- solid MS ( $1 \%$ of phytagel) with $0.05 \%$ of carbendazim for two weeks, which resulted in a $100 \%$ disinfection without mortality of the cuttings (Fig. 3). Present results on disinfection with carbendazim in semi-solid medium surpassed those obtained by Castro and Álvarez (2013), who achieved a disinfection of only $45 \%$ in V. meridionale with carbendazim in solid medium, and no obvious damage was observed to the plants.
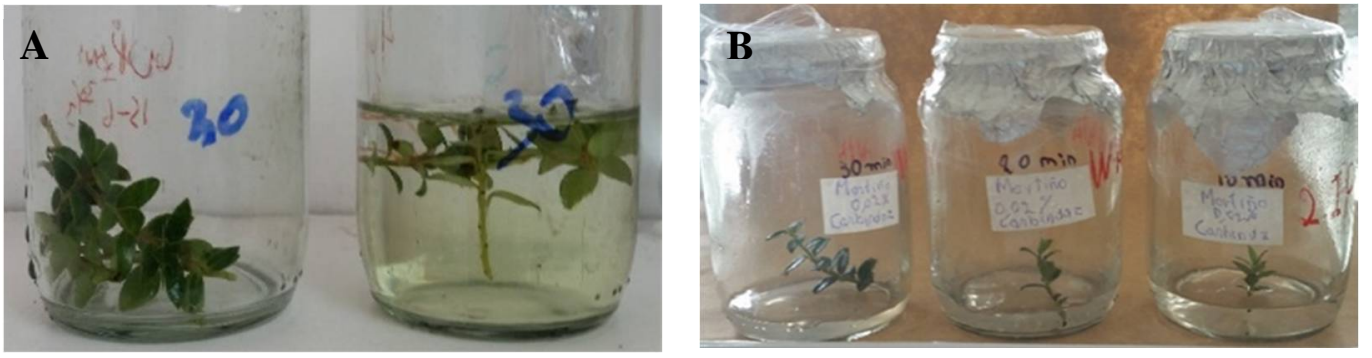

Fig. 3. A. Disinfection with $2 \% \mathrm{ClO}_{2}$, B. Carbendazim (0.1, 0.5 and $\left.1 \%\right)$ in MS.

The woody plant medium (WPM), is considered to have low salt concentration, and it is suitable for the cultivation of Vaccinium (Debnath 2009). Numerous studies have shown that the WPM medium was the most suitable for the growth of shoots when compared to other seven media tested in the cranberry variety "Bluecrop" (Rodríguez et al. 2015, Cüce et al. 2013). From this study, most of the workers have used WPM as a basal medium for the micropropagation of blueberries (Wolfe et al. 1983). Micropropagation is the most successful technique used for blueberry propagation (Silva et al. 2008). 
In this study, the combination with the highest concentration of BAP and IAA (10 $\mu \mathrm{M})$ resulted in better establishment and sprouting of cuttings, obtaining a multiplication rate of 3.35 (Fig. 4 A-C), which was similar to the multiplication rates (3.3 and 2.66) in the Brigitta and Legacy varieties of $V$. corymbosum L. respectively (Rodríguez and Morales 2015). Different concentrations of BAP have been evaluated in V. floribundum, and indicated that the buds require high concentrations of BAP for their development (Cobo et al. 2018).
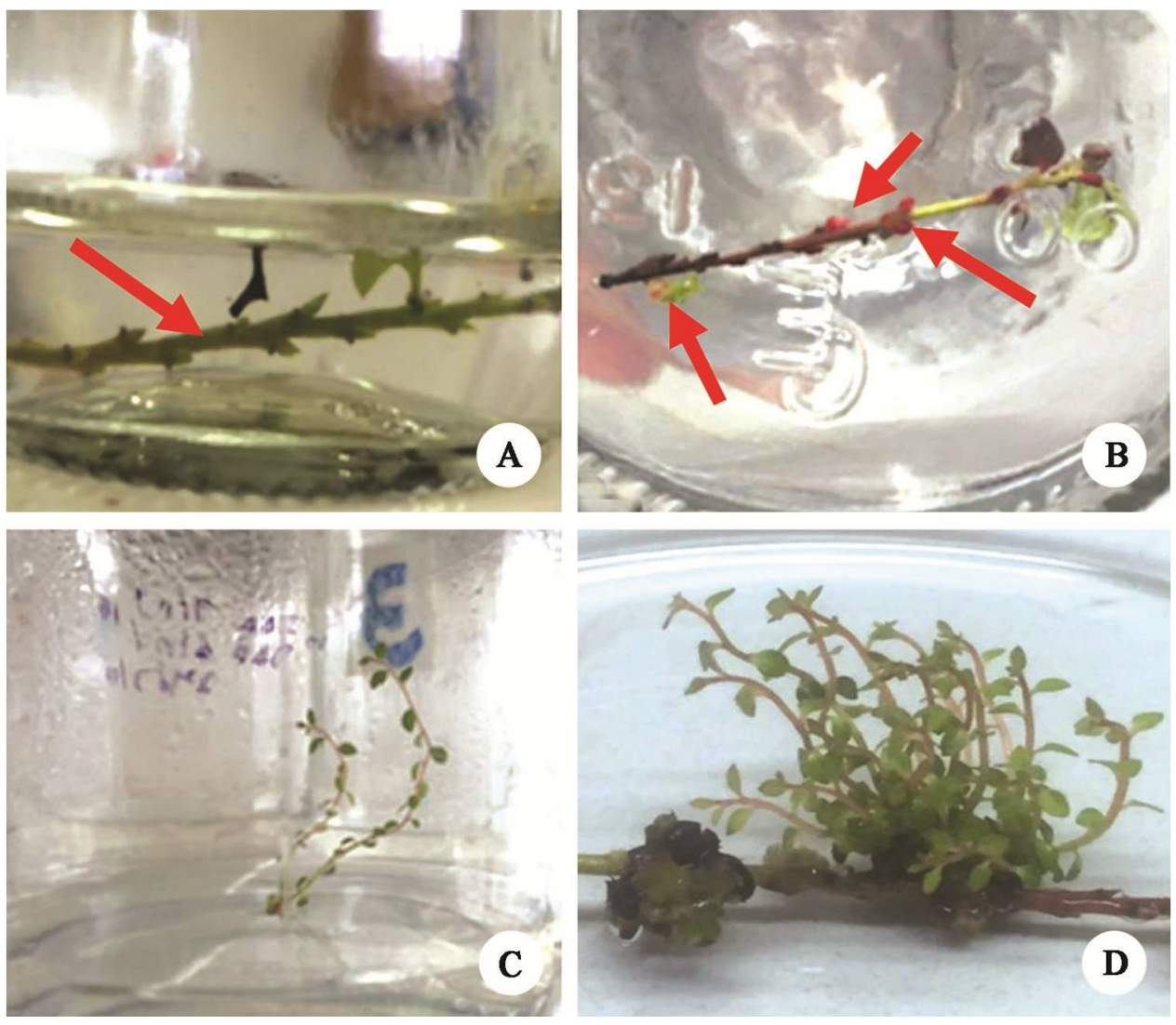

Fig. 4. Establishment and sprouting of cuttings in WPM medium supplemented with IAA and 10 $\mu \mathrm{M}$ BAP. A. Innoculated cuttings in the medium, B. 3 buds of 3 weeks, C. First generation, D. Explant sprouting after five weeks of in vitro growth in WPM medium.

It has been confirmed that the spray of BAP, delays senescence by maintaining concentrations of chlorophyll, soluble proteins, and Rubisco. It also modifies enzymatic activity, retains a high content of sugars, and reduces the loss of electrolytes (González et al. 2009). These effects may be related to sprouting of cuttings caused by the high concentration of BAP $(10 \mu \mathrm{M})$ on cuttings of $V$. floribundum, with unknown information (age and genetic background of the accession) for their wild status. 
Previous reports showed that the density of 25 explants per bottle, with high volumes of WPM medium, gave the best propagation results in $V$. corymbosum $\mathrm{L}$. (Rodríguez and Morales, 2015). However, the MS induced necrosis of stems and leaves in explants of lingonberry cultivars, which was more visible on media containing zeatin (Ruzić et al. 2012).

IAA inhibited the development of lateral axillary buds, maintained apical dominance, stimulated the production of apical buds and did not cause calli (Fig. 4D), as reported in other studies (Ferguson and Beveridge 2009, Silva et al. 2008) showed that IAA was the regulator suited for the culture medium in the in vitro establishment of blueberry ( $V$. ashei). Regulation is achieved through an auxins/cytokinin's balance (Rojas et al. 2004). It has also been observed that BAP at $8.9 \mu \mathrm{M}$ improves the proliferation of shoots of Vaccinium uliginosum, with the addition of $5.8 \mu \mathrm{M}$ of gibberellic acid $\left(\mathrm{GA}_{3}\right)$. Unlike the TDZ that induced a hyperhydricity of 20 - 30\% (Gu et al. 2009), results similar to Pelizza et al. (2010).

It is known that WPM is ideal to increase the percentage of rooting given its low amount of nutrients (Acosta et al. 2011). Therefore, the application of the method based on the depletion of nutrients induced rooting after two and a half months. It should be noted that these are very important preliminary results, and that it is recommended to analyze the functionality of these roots in future work.

The two and a half months of nutrient depletion of the explants were enough to induce rooting, promoting the formation of adventitious roots in the explants. According to Chávez and De Feria (2012), the rhizogenesis or induction and development of a functional radicular system, constitutes are one of the limiting barriers for micropropagation in certain woody species. Therefore, it is recommended to carry out a study aiming at the $V$. floribundum rooting, and to verify if these roots are functional.

Researchers have stressed the recalcitrant qualities of mortiño and the difficulty of using conventional strategies for propagating $V$. floribundum Kunth., which has prevented the formal cultivation of this species (Cobo et al. 2018). In addition of being an endemic species, it is a very promising shrub, suggesting a potential risk of extinction due to the increased use of this plant and the lack of propagation methods (Sharma and Bora 2016). However, standardized micropropagation protocols of mortiño cannot be found in the literature.

Finally, it was possible to obtain an optimal disinfection methodology consisting in chlorine dioxide at $2 \%$ for 10 minutes and fungicide carbendazim at $0.5 \%$ for two weeks was established for the wild species $V$. floribundum and an adequate in vitro propagation protocol was obtained with a multiplication rate of 3.35 from the fifth week of sowing with the formulation of the modified WPM media with a concentration of $10 \mu \mathrm{M}$ of IAA and BAP. 


\section{Acknowledgment}

This work was supported by the International Foundation for Science (IFS), Grant No. D/5451-1. Also, it was a part of an interuniversity agreement supported by the VLIR Network Ecuador. This work was carried out under the strict rules and supervision of the Ministry of the Environment MAE-DNB-CM-2017-0055.

\section{References}

Acosta A, Peña E and Castro D (2011) Evaluation of culture media for in vitro production of Annona muricata using the serial grafting technique. Acta Agronómica 60(2): 140-146.

Angulo A, Castillo R and Gómez-Alpízar L (2015) Micropropagación de cuatro cultivares de arándano (Vaccinium spp.) a partir de segmentos foliares de dos procedencias. Agronomía Costarricense 39(1): 7-23.

Babu KD, Sathiamoorthy S, Chezhiyan N and Singh KD (2004) Gentamycin and carbendazim for axillary bud culture of papaya (Carica papaya L.) in vitro. Asian Journal of Microbiology, Biotechnology and Environmental Sciences 6(2): 309-311.

Cardoso J and Teixeira J (2012) Micropropagation of gerbera using chlorine dioxide $\left(\mathrm{ClO}_{2}\right)$ to sterilize the culture medium. In Vitro Cellular \& Developmental Biology - Plant 48(3): 362-68.

Castro D and Álvarez J (2013) Clonal micropropagation of three genotypes of mortiño, Vaccinium meridionale SW., by axilary shoots proliferation. Actualidades Biológicas 35(99): 145-160.

Chávez M and De Feria M (2012) Basic aspects of in vitro propagation of Pinus genus by organogenesis. Biotecnología Vegetal 12: 131-142.

Cobo M, Gutiérrez B, Torres A and Torres M (2016) Preliminary analysis of the genetic diversity and population structure of mortiño (Vaccinium floribundum Kunth.). Biochemical Systematics and Ecology 64: 14-21.

Cobo M, Gutiérrez B and Torres M (2018) Regeneration of mortiño (Vaccinium floribundum Kunth.) plants through axillary bud culture. In Vitro Cellular \& Developmental Biology - Plant 54(1): 112-116.

Cüce M, Bektaş E and Sökmen A (2013) Micropropagation of Vaccinium arctostaphylos L. via lateral-bud culture. Turkish Journal of Agriculture and Forestry 37: 40-44.

Debergh, PC, Coster G and Steurbaut W (1993) Carbendazim as an alternative plant growth regulator in tissue culture systems." In Vitro Cellular \& Developmental Biology - Plant 29(2): 89-91.

Debnath, SC (2009) Propagation and cultivation of Vaccinium species and less known small fruits Vaccinium ăints sugu un mazāk zināmo augěaugu pavairošana un audzēšana. Acta Horticulturae. Applied Microbiology International Journal of Food Science and Technology 390(10): 1011-1015.

Ferguson B and Beveridge C (2009) "Roles for auxin, cytokinin, and strigolactone in regulating shoot branching. Plant Physiology 149(4): 1929-1944.

González R, Delgado A, Zavaleta A and Herrera E (2009) Cytokinin BAP promotes the accumulation of hexoses and increases the activity of phosphoenolpyruvate carboxylase and phosphoenolpyruvate carboxykinase during the delay of leaf senescence in wheat. Agrociencia 43(4): 379-391. 
Gu D, Gu M, Jiang Y, Gao H and Zhu J (2009) In vitro culture and plant regeneration system of Vaccinium uliginosum. Forest Research 22(2): 226-229.

Howell AB (2009) Update on health benefits of cranberry and blueberry. Acta Horticulturae 810: 779-785.

Korneva S, Flores J, Santos E, Piña F and Mendoza J (2013) Plant regeneration of plantain 'barraganete' from somatic embryos using a temporary immersion system. Biotecnología Aplicada 30(4): 267-270.

Litwińczuk W (2012) Micropropagation of Vaccinium sp. by in vitro axillary shoot proliferation. In Methods in Molecular Biology (Clifton, N.J.) 11013: 63-76.

Llivisaca S, Manzano P, Ruales J, Flores J, Mendoza J, Peralta E and Cevallos-Cevallos JM (2018) Chemical, antimicrobial, and molecular characterization of mortiño (Vaccinium floribundum Kunth.) fruits and leaves. Food Science \& Nutrition 6(4): 934-942.

Medina C, Lobo M, Álvaro A and Cardona L (2015) Development analysis of mortiño (Vaccinium meridionale Swart) plants derived from clonal and sexual propagation. Corpoica Ciencia y Tecnología Agropecuaria 16(1): 65-77.

Pelizza TR, Carvalho GL and Schuch MW (2010) Growth evaluation of blueberry minicuttings under different growth regulators. Acta Horticulturae 884: 623-28.

Podwojewski P (1999) Los suelos de las altas tierras andinas: Los páramos del Ecuador. Boletin informativo - Sociedad Ecuatoriana de la Ciencia del Suelo 18: 9-14.

Rodríguez M and Morales D (2015) Effect of explant density and volume of cultivation medium on in vitro multiplication of blueberry (Vaccinium corymbosum L.) Varieties 'Brigitta' and 'Legacy'. Scientia Agropecuaria 6(1): 31-40.

Rojas S, García J and Alarcón M (2004) Propagación asexual de las plantas: conceptos básicos y experiencias con especies amazónicas isbn: 958-8210 57-7.

Ruiz H (2011) Desarrollo de un vino de mortiño en la corporación gruppo salinas de Ecuador. Universidad Pública De Navarra. https://academica-e.unavarra.es/xmlui/handle/2454/3447

Ruzić D, Vujović T, Cerović R, Ostrolucka MG and Gajdosova A (2012) Micropropagation in vitro of highbush blueberry (Vaccinium corymbosum L.). Acta Horticulturae 926: 265-272.

Saha S and Behera TK (2015) Standardization of techniques for in vitro multiplication of gynoecious line in bitter gourd. Vegetos 28(4): 48-53.

Schreckinger M, Wang J, Yousef G, Lila M and Gonzalez E (2010) Antioxidant capacity and in vitro inhibition of adipogenesis and inflammation by phenolic extracts of Vaccinium floribundum and Aristotelia chilensis. Journal of Agricultural and Food Chemistry 58(16): 89668976.

Sharma R and Sunil B (2016) In vitro sterilization protocol of Vanilla planifolia explants for micropropagation. Natural and Social Sciences 4: 135-142.

Silva J, Winarto B, Dobránszki J and Zeng S (2015) Disinfection procedures for in vitro propagation of Anthurium. Folia Horticulturae 27(1): 3-14.

Silva L, Márcia S, Souza J, Erig A and Antunes L (2008) Tipo de ramo e efeito do ácido indal acético (aia) no estabelecimento in vitro de três cultivares de mirtilo. Ciência Rural 38(2): 522-525.

Silva S, Costa E, Costa M, Pereira M, Pereira J, Soares J and Pintado M (2015) Aqueous extracts of Vaccinium corymbosum as inhibitors of Staphylococcus aureus. Food Control 51: 314-320. 
Srichuay WT, Promchan and Te-Chato S (2018) Effect of chlorine dioxide $\left(\mathrm{ClO}_{2}\right)$ on culture medium sterilization on micropropagation of Persian violet (Exacum Affine Balf.f. Ex Regel). International Journal of Agricultural Technology 14(2): 259-270.

Tecsaclor (2009) Nueva alternativa en desinfectantes: dióxido de cloro en portal industrial. https://www.portal-industrial.com.ar/index.php/news /main/ $310 /$ event=view.

Torres M, Trujillo D and Arahana V (2010) Cultivo in vitro del mortiño (Vaccinium floribundum Kunth.). ACI Avances en Ciencias e Ingenierías 2(2): B9-B15.

Wolfe DE, Eck P and Chin CK (1983) Evaluation of seven media for micropropagation of highbush blueberry. HortScience 18(5): 703-705.

(Manuscript received on 29 July, 2020; revised on 24 August, 2020) 